\title{
La articulación del espacio doméstico en las casas de patio central. Un estudio para el Noreste peninsular ibérico entre los siglos IV - II a. C.
}

\author{
Domestic space organization in courtyard houses. A study of the East Iberian \\ Peninsula during 4 th and 2 nd century B.C
}

\author{
Gloria Fernández García \\ Universidad de Zaragoza, Campus de Teruel. \\ Grupo de investigación Hiberus \\ gloriafg@unizar.es
}

\begin{abstract}
RESUMEN
Presentamos un estudio comparativo diacrónico a través de la metodología analítica de la sintaxis espacial de un conjunto de casas de patio del este de la Península Ibérica datadas entre el siglo IV y el II a. C., periodo anterior e inmediatamente posterior al inicio de la conquista romana de esta región. Estas grandes casas complejas y con patio han sido interpretadas como las residencias de grupos minoritarios y poderosos: las aristocracias locales. $\mathrm{A}$ partir de esta idea trataremos de conocer el comportamiento y evolución de esta clase social durante el periodo de cambio que abordamos. La aplicación de un análisis sintáctico del espacio sobre una serie de casos nos ha permitido conocer las diferentes connotaciones que pueden adquirir las casas con patio. La principal diferencia entre las casas prerromanas e hispanorromanas está marcada por la mayor complejidad sintáctica de las primeras, que procede de las formas de la tradición indígena.
\end{abstract}

Palabras clave: casas de patio; casas complejas ibéricas; sintaxis espacial del espacio doméstico; protohistoria del Mediterráneo; élites.

\begin{abstract}
In this paper we approach a diachronic comparative study through space syntax analysis methodology of a set of courtyard houses from the East of the Iberian Peninsula dated between the IVth century and the IInd B.C., period previous and immediately to the beginning of Roman domination of these regions. These big complex houses with courtyard have been interpreted as the residences of minority powerful groups, that is to say, local aristocracy. In view of this, we shall try to study the evolution of this social class during this period characterized by economic and politic changes. Domestic space syntax analyses allows us to see the consequences of the adoption of formal changes in houses, for the social relationships. The high syntactic complexity observed in protohistorical houses is the main difference between these and roman houses.
\end{abstract}

Keywords: courtyard houses; iberic complex houses; space syntax analysis; Mediterranean protohistory; elites.

Recibido: 19-05-2015. Aceptado: 11-08-2015.

Cómo citar este artículo / Citation

Fernández García, G. 2015: "La articulación del espacio doméstico en las casas de patio central. Un estudio para el Noreste peninsular ibérico entre los siglos IV - II a. C.", Arqueología de la Arquitectura, 12: e033. doi: http://dx.doi.org/10.3989/arq.arqt.2015.123

\section{Copyright}

(c) 2015 CSIC. Este es un artículo de acceso abierto distribuido bajo los términos de la licencia Creative Commons Attribution-Non Commercial (by-nc) Spain 3.0. 


\section{INTRODUCCIÓN}

La problemática que a continuación desarrollamos se contextualiza históricamente en el periodo de cambios que tienen lugar entre el siglo IV y el siglo II a. C. en las regiones del litoral mediterráneo de la península ibérica y en el interior, en el Sistema Ibérico, definidas como el ámbito ibérico y el celtibérico durante la Protohistoria. Este periodo, que a escala mediterránea se denomina tardo-helenístico, se caracteriza por el incremento de las relaciones entre diferentes áreas regionales y culturales, la circulación de productos e ideas y la continuación de las colonizaciones que culminarán con el proyecto expansionista romano. En consecuencia, en los diferentes procesos de transformación que tienen lugar durante este periodo, intervienen tanto las dinámicas de cambio locales como las influencias externas, coordenadas entre las que se sitúa nuestro análisis.

Proponemos acercarnos a este momento histórico a través del registro arqueológico del espacio doméstico. Los numerosos trabajos ${ }^{1}$ en los que hasta ahora se ha desarrollado este enfoque, confirman la validez que desde el inicio se confirió a su estudio. De acuerdo con las premisas de la arqueología espacial, uno de los ámbitos donde comenzó a desarrollarse la arqueología de los espacios domésticos, el estudio de la vivienda representaba el nivel mínimo de resolución del registro arqueológico y nos acercaba a la comprensión de aspectos como "la economía del núcleo doméstico, las relaciones de género, la división del trabajo, la estratificación social, el estatus social, aspectos ideológicos o el análisis de los modos de vida" (Clarke 1977: 11).

El estudio de los aspectos referidos nos resulta de suma importancia para comprender un periodo de transición como el de los siglos III y II a. C. en la península ibérica. Consideramos que los procesos de cambio tienen lugar de forma paulatina, y de ello da constancia el ritmo lento en la mutación de las costumbres y los modos de vida dentro de las unidades domésticas. De tal manera que el espacio doméstico será clave para comprender la dialéctica del cambio, en el que sus habitantes desempeñan un papel tanto de agentes

\footnotetext{
1 La arqueología de los espacios domésticos cuenta con un arraigo en la disciplina desde los años 70 y su desarrollo ha tenido lugar dentro de diferentes corrientes y escuelas hasta la actualidad. Sin embargo no es nuestro objetivo sintetizar en el presente trabajo sus bases teóricas y su prolífica literatura. Para una visión completa remitimos a los siguientes trabajos de síntesis enfocados a su desarrollo en la península ibérica: Azcárate 2008; Bermejo 2014b, 2014a: 41-79; Mañana, Blanco, y Ayán 2002; Adánez 2003.
}

receptivos como de promotores del mismo. Con este planteamiento pretendemos definir el proceso histórico previo a la romanización del Mediterráneo Occidental partiendo de las casas con patio como un símbolo de la transformación o una de las tantas materializaciones del cambio.

\section{LAS CASAS CON PATIO ENTRE LOS SIGLOS IV Y II a. C. EN EL OCCIDENTE MEDITERRÁNEO}

Las casas complejas y con patio del Levante peninsular ibérico durante la Protohistoria

Durante la Protohistoria en el nordeste peninsular y el Levante, una parte de todo el ámbito definido culturalmente como ibérico, la edilicia doméstica se escapa a cualquier intento de estandarización; el emplazamiento de las viviendas, así como la organización del asentamiento donde se encuentran, da pie a una gran diversidad. Tan solo ha sido posible identificar la tendencia a organizar el espacio en estructuras cuadrangulares, dentro de las cuales ha sido posible reconocer lugares destinados a la molienda y otras actividades culinarias y al almacenaje de productos en algunas de las casas excavadas (Belarte, Bonet y Sala 2009: 98).

Dependiendo de la compartimentación interior, estas actividades conviven en el mismo espacio o aparecen segregadas, pero siempre se mantienen espacios en torno al hogar que permiten albergar funciones de cocina, molienda, estancia colectiva o trabajos artesanales; es frecuente, sin embargo, la separación de la zona para el almacenaje en una estancia separada o sencillamente hacia el fondo de la casa en el mismo espacio (Belarte 2008: 182-184; Belarte, Bonet y Sala 2009: 98-99). La organización interior junto con el tamaño de las casas, son los principales factores que han llevado a su clasificación en dos tipos: casas simples y casas complejas (Belarte 1997: 153-156; Belarte 2008: 179; Belarte, Bonet y Sala 2009: 98; Belarte 2013: 78). En el último tipo de casas se incluyen aquellas que "poseen superficies superiores a $50 \mathrm{~m}^{2}$, a menudo superan $\operatorname{los} 100 \mathrm{~m}^{2}$ (la mayor de ellas alcanza incluso los $800 \mathrm{~m}^{2}$ ); pueden tener planta rectangular o cuadrada y están subdivididas en un mínimo de 4 estancias. Estas residencias pueden incluir patios o corredores de acceso a las distintas estancias" (Belarte 2013: 78).

El análisis de la organización del espacio en estas viviendas atendiendo a su diseño, la funcionalidad y la 
interconexión entre las divisiones interiores, realizado por Grau (2013), considera estas viviendas dentro de los tipos de "casa monofocal compleja" y "casa plurifocal" (Grau 2013: 62-64), siendo el hogar el elemento nuclear y articulador. En el primer grupo encontraremos casas con un solo hogar y varias estancias, y en el segundo varias estancias donde se encuentran hogares en alguna de ellas. En ambos se repiten los espacios abiertos o patios. Ilustran esta tipología edilicia una serie de yacimientos del ámbito valenciano: La Sénia, Villares de Caudete de las Fuentes (Kelin), La Bastida de los Alcusses, El Oral (Grau 2013); y del catalán: Illa d'en-Reixac y el Puig de Sant Andreu en Ullastret, El Castellet de Banyoles en Tivissa, Alorda Park en Calafell, El Puig Castellar de Santa Coloma de Gramenet, Mas Castellar de Pontós y Fondo del Roig de Cunit (Belarte 2013).

Estas viviendas, con una representación minoritaria en el urbanismo del asentamiento en el que se encuentran, tienen también elementos arquitectónicos que no posee el resto de las casas - columnas, pavimentos elaborados a base de opus signinum, revestimientos de mortero de cal一, así como signos indicadores de riqueza -altos porcentajes de cerámica de importación-, y concentración de ciertos materiales como pesas de telar, molinos, etc. (Belarte 2013: 86), y suelen situarse en lugares de importancia en la estructura del asentamiento. La introducción de las casas complejas en el nordeste, tanto en asentamientos urbanos como en pequeñas aldeas rurales, forma parte de un proceso de cambio más profundo que tiene lugar durante el Ibérico Pleno, es decir, entre los siglos IV y III a. C. y que se manifiesta igualmente con la aparición de los primeros rasgos que pueden ser calificados de urbanos en la organización interior de los oppida, así como en la introducción de innovaciones en la arquitectura defensiva y sacra y en los enterramientos (Moret 2006: 207-208). Sin embargo, en el sur y en el levante las casas complejas se documentan ya a partir del s. V a. C., como en el poblado de El Oral sobre el que nos detendremos más adelante. En ambos contextos la aparición del patio supone un cambio, y en cierto modo una ruptura, con la tradición doméstica indígena que en ocasiones se ha asociado a influencias externas. La relación que las casas con patio guardan con su entorno físico, aisladas del exterior y construidas hacia el interior para aprovechar la luz, permitiría apoyar el desarrollo local de la vivienda de patio. No obstante, como defienden Sala y Abad (2006: 36) es "la falta de precedentes lo que lleva a relacionar estas casas con impulsos externos".

\section{El Oral: La Casa IVH}

En el asentamiento de El Oral (San Fulgencio, Alicante) (Sala y Abad 2006) (fig. 1) son varias las casas complejas que se disponen a ambos lados de una calle central; las de patio se encuentran en el lado Este adosadas a la muralla. La unidad constructiva 19 se organiza en torno a un patio con un canal de desagüe decorado con conchas que, como en los ejemplos que siguen, recoge el agua procedente del área abierta y lo evacua hacia fuera de la muralla. De igual manera se dispone la Unidad constructiva 18. En la casa IVA, el patio se antepone al resto de la casa y en la Casa IVH, $209 \mathrm{~m}^{2}$, el patio que corresponde a la segunda fase de ocupación, tiene un acceso en codo y ocupa el centro de la vivienda (Sala y Abad 2006: 28-34).

Las casas IIIG y IIIK son igualmente de grandes dimensiones y podrían clasificarse como complejas por su compartimentación interior, pero carecen de patio. La primera de ellas repite el esquema de espacio central en " $T$ " que encontramos en otras del mismo asentamiento. La casa IIIK es de estructura compleja y bastante original y no se asemeja al resto. En el interior de estas viviendas destacan materiales de gran valor en contraste con una arquitectura más humilde (Sala y Abad, 2006: 34-35).

Nos interesa detenernos en la casa IVH cuyas dimensiones $\left(280 \mathrm{~m}^{2}\right)$ son superiores al resto y con dos fases constructivas (fig. 2a). Desde el inicio se dispone un espacio central abierto empedrado con guijarros que, en la siguiente fase datada a finales del siglo IV a. C., se cierra en el extremo noroccidental con un tabique; y lo mismo en el lado opuesto para crear así dos estancias más. La entrada se mantiene en el lado noroccidental y crea un acceso en codo hacia el patio. En la interpretación del uso y funcionalidad de las habitaciones se han tenido en cuenta principalmente los dispositivos y elementos constructivos detectados en cada una de ellas (Sala y Abad 2006: 30-31). Las dos habitaciones centrales situadas en el lado este de la vivienda servirían como lugares de reunión, comida o reposo, según indican los materiales constructivos. En una de ellas, la más al sur, el suelo estaba empedrado con guijarros con función aislante, en el centro se disponía una mesa hecha con un adobe y las paredes estaban pintadas. En la otra, más al norte, el pavimento estaba construido con adobes cubiertos por finas capas de yeso y ceniza alternativamente y las paredes estaban igualmente decoradas con pinturas. Las dos estancias situadas en los extremos de este 


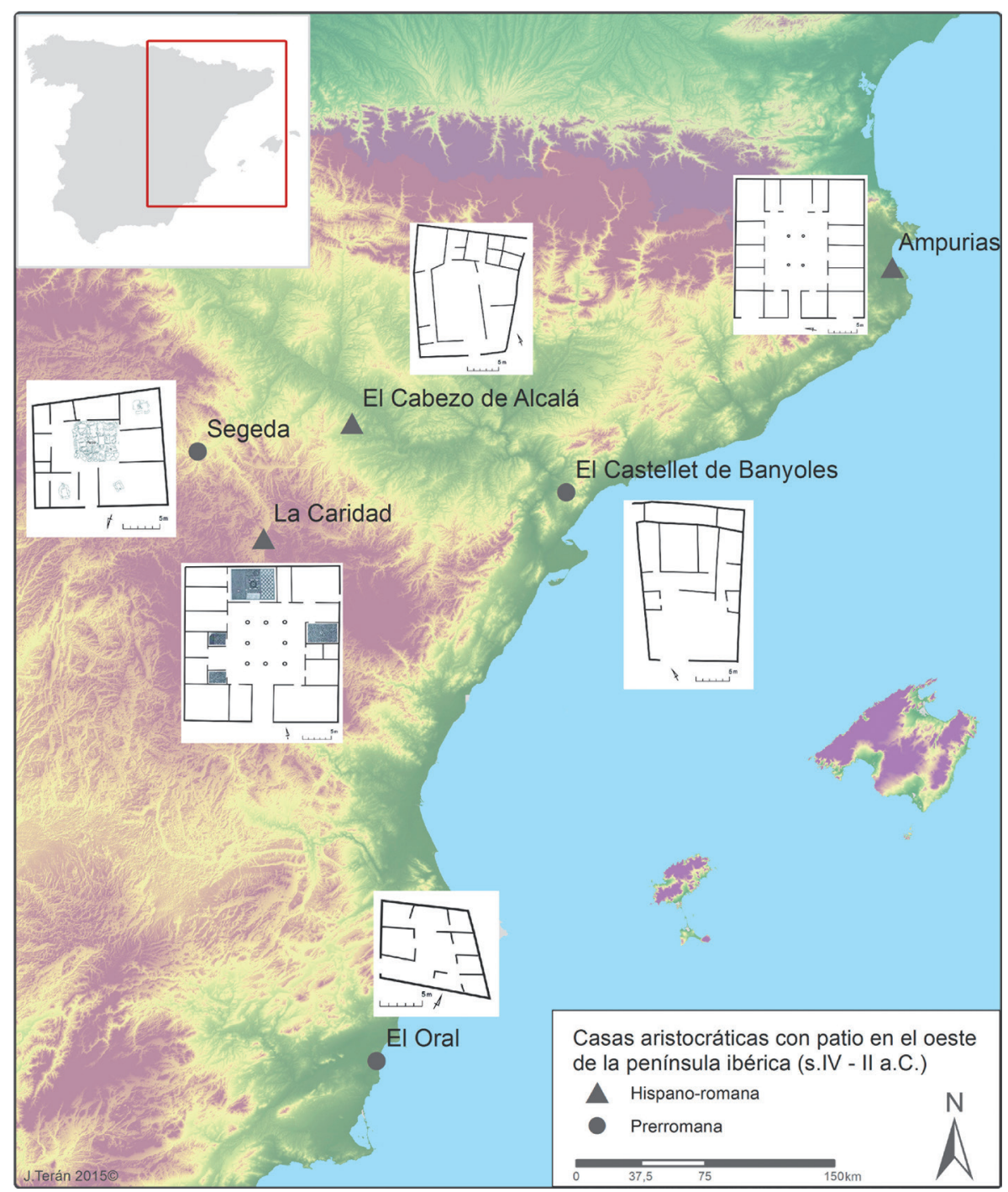

Figura 1. Localización de los yacimientos con casas de patio analizados en el presente trabajo. mismo flanco serían almacenes, según indica el tipo de materiales cerámicos hallados en su interior, así como el tipo de suelo construido con adobes cubiertos de arcilla, a modo de aislante, que ha sido localizado en la habitación del ángulo sureste. Igualmente, la estancia creada en la segunda fase, al lado de ésta y frente a la entrada, se ha interpretado como almacén. La habitación central del otro lado del patio, en la parte oeste, tenía el papel de la habitación noble, según se desprende de su posición central, su gran tamaño, así como del suelo sobreelevado cubierto de guijarros. Al norte de esta habitación, el espacio situado en el ángulo ha sido considerado como un área de trabajo, al lado de la cocina, que estaría al fondo norte del patio (Sala y Abad 2006: 30-31).

Para sus excavadores, esta vivienda comporta un carácter complejo por los desagües, así como los acabados interiores o el empedrado del patio; afirman que se trataría de una "residencia privilegiada, con una planta bastante racional, imposible de explicar por un paulatino proceso de mejora de la vivienda tradicional" (Sala y Abad 2006: 38).

\section{El Castellet de Banyoles de Tivissa}

Las excavaciones recientes (Asensio 2002) han permitido datar en el siglo III a. C. los trabajos de construcción que modifican completamente la fisionomía del asentamiento y la ocupación anterior parece ser bastante modesta. En la arquitectura doméstica a. C., organizada en torno a un trazado viario bien definido en su parte norte (Sanmartí, Asensio, Miró y Jornet 2012: 47-49), las dieciséis viviendas identificadas se pueden definir como complejas, a pesar de la gran diversidad formal entre ellas. Tres, edificios, el 1, el 2 y el 3, cuyas dimensiones 
a

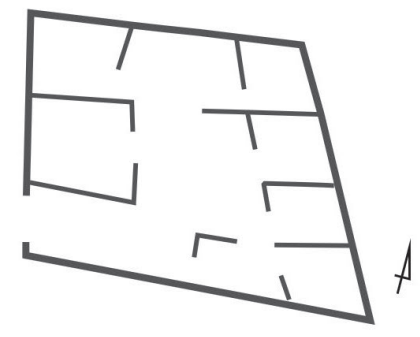

C

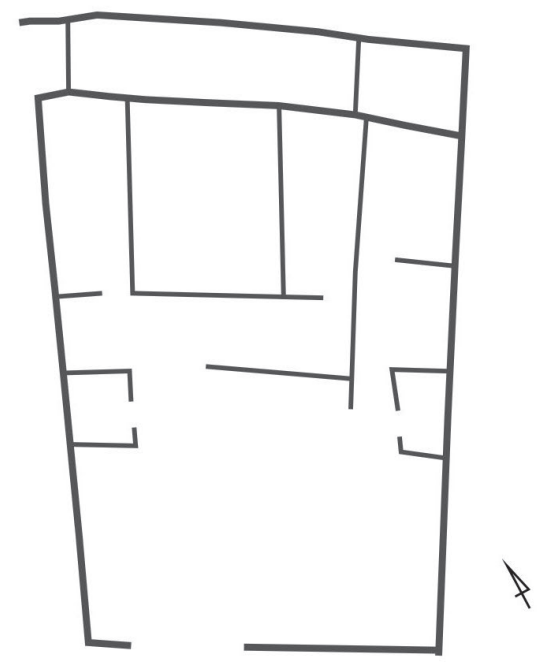

$\boldsymbol{\theta}$

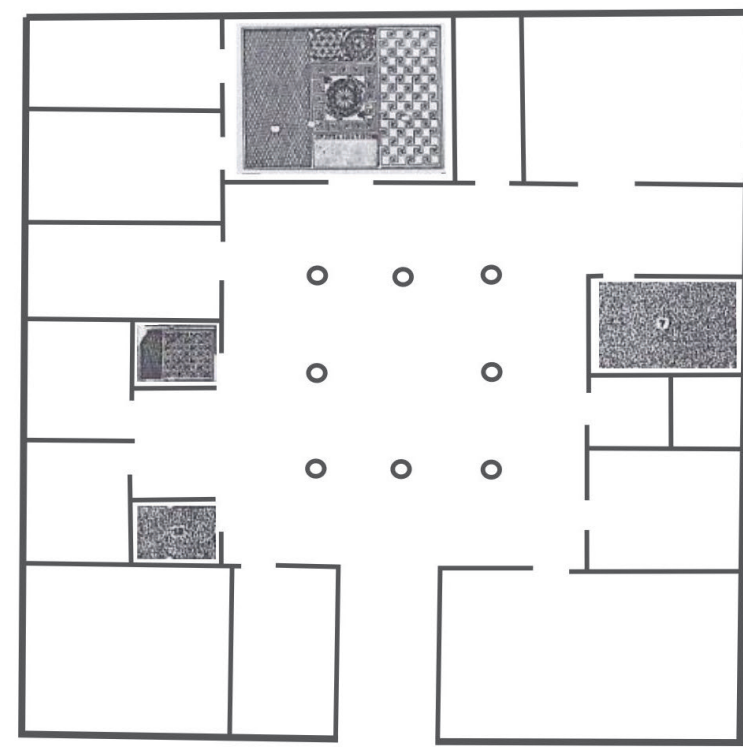

b
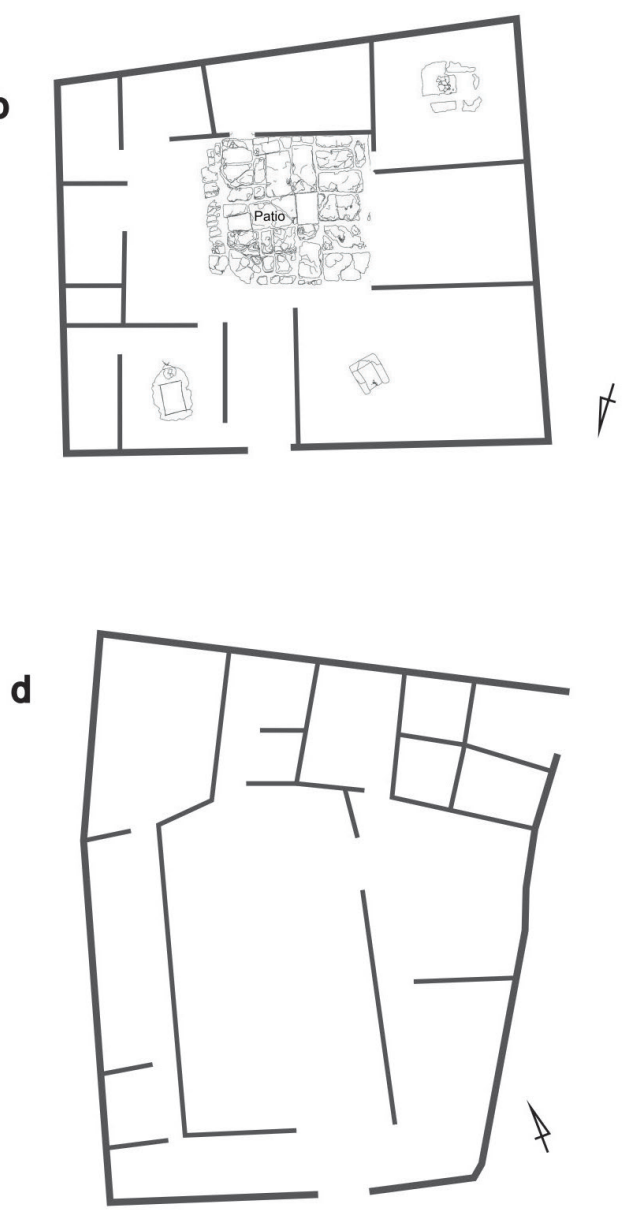

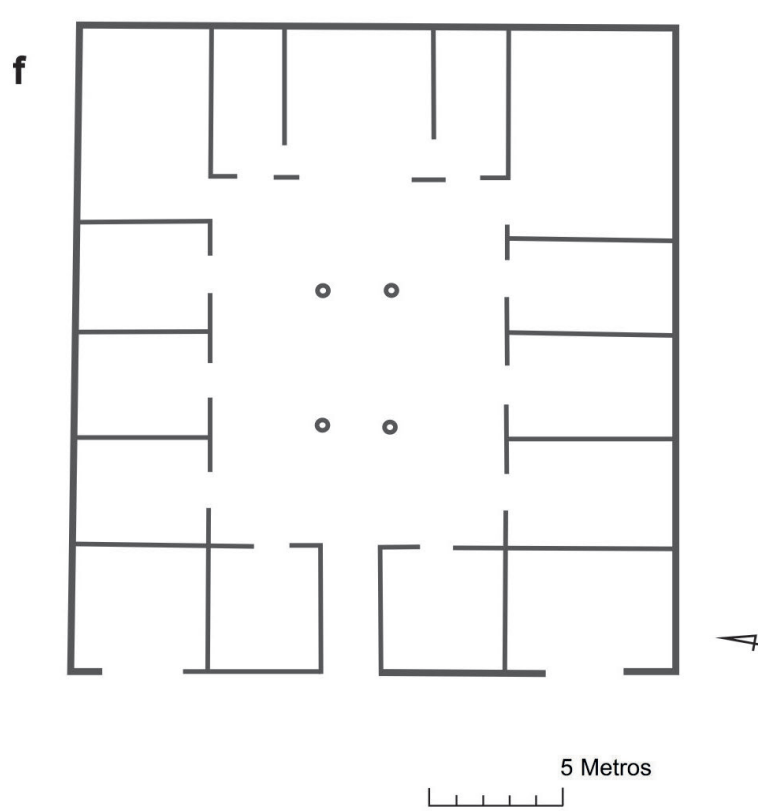

Figura 2. Representación esquemática de las plantas de las casas analizadas en el presente trabajo. a: Casa VHI de El Oral (a partir de Sala y Abad 2006: 30, fig. 5); b: Casa del estrígilo de Segeda I; c: Casa 2 de El Castellet de Banyoles (a partir de Asensio, Sanmartí, Jornet, Miró, 2012: 179, fig. 5); d: Casa 2D de El Cabezo de Alcalá de Azaila (a partir de Beltrán 1976: 143, fig. 40); e: Casa de Likine de La Caridad (a partir de Vicente, Punter, Escriche y Herce 1991: 86, fig. 7); f: Casa número 1 de Ampurias (a partir de Santos 1991: 24, fig.5). 
son de $275 \mathrm{~m}^{2}, 350 \mathrm{~m}^{2}$ y $260 \mathrm{~m}^{2}$ respectivamente, están precedidos de grandes patios. Según sus excavadores, a pesar de la dificultad que conlleva la datación del momento inicial de este sistema urbanístico, los niveles de uso de estas viviendas permiten interpretar la vida en ellas de dos generaciones y sitúan su construcción aproximadamente medio siglo antes de la destrucción del asentamiento que tuvo lugar en torno al 200 a. C., es decir, en el tercer cuarto del siglo III a. C. (Álvarez, Asensio, Jornet, Miró y Sanmartí 2008: 89- 90; Sanmartí, Asensio, Miró y Jornet 2012: 49-50). La estructura interior de estas tres viviendas adosadas a la muralla es casi la misma: un patio delantero que da acceso a las habitaciones, precedidas éstas por un espacio transversal a modo de pórtico o distribuidor que recuerda la pastas de algunas casas griegas (fig. 2b). El centro del espacio doméstico en cada casa está marcado por la única habitación que dispone de hogar y que sería la cocina. Las funciones del resto de las habitaciones no han sido definidas debido a la escasez de material documentado in situ (Álvarez, Asensio, Jornet, Miró y Sanmartí 2008: 91; Sanmartí, Asensio, Miró y Jornet 2012: 55). Entre los materiales hallados se encuentra la mayor concentración de signos de riqueza de todo el asentamiento; lo que se ha interpretado como las lujosas residencias de familias pertenecientes a las clases dirigentes (Álvarez Asensio, Jornet, Miró y Sanmartí 2008: 98).

\section{La arquitectura doméstica en el interior peninsular: el Sistema Ibérico durante la Protohistoria}

Según se ha puesto en evidencia en varias ocasiones, la escasez de datos procedentes de yacimientos excavados en la región del interior peninsular que pretendemos abordar en este epígrafe, denominada Celtiberia en los textos clásicos, dificulta la tarea de reconstruir o trazar el panorama de la arquitectura y los espacios domésticos. Sin embargo, este hecho no ha impedido la lectura del registro disponible, que no debe menospreciarse, y el planteamiento, no tanto de conclusiones como de posibles líneas interpretativas.

En líneas generales se puede afirmar que los patrones urbanísticos comienzan a presentar bastante heterogeneidad y complejidad a partir de inicios del s. V a. C., es decir, a partir de la II Edad del Hierro. En este momento se documenta la ampliación de los pequeños asentamientos que entre los siglos VII y $\mathrm{V}$ a. C. se habían ido consolidando y constituían las formas de hábitat típicamente protohistóricas de esta región. Se caracterizaban por un trazado bastante regular y casas de dimensiones muy similares, adosadas al muro de cierre externo (Arenas 2011: 136; Ortega 1999: 427-428). A partir del s. V a. C. los poblados adquieren formas diversas y se reparten desigualmente en el territorio; dentro de ellos aumenta la superficie construida con edificios para la producción artesanal y el almacenaje, se reduce el espacio colectivo y se construyen calles que articulan el urbanismo (Arenas 2010: 347; Arenas 2011: 139-140), según muestran las excavaciones de algunos de los yacimientos del Sistema Ibérico como La Coronilla de Chera, la fase II de El Ceremeño en Herrería (Cerdeño, Chordá y Gamo 2014), El Palomar en Aragoncillo (Arenas 1999) o Peña Moñuz (Arlegui 1992). Las viviendas se construyen en base a una "planta angular con un módulo heterogéneo que produce espacios de diversa morfología y que rara vez rebasan los $40-50 \mathrm{~m}^{2}$ de superficie útil. (...) En algunos casos, las unidades domésticas alcanzan cierta complejidad dado que parecen estar compuestas por varios edículos de distinta funcionalidad" (Arenas 2011: 138). La interpretación al uso hasta no hace mucho, que identificaba una unidad doméstica por cada construcción rectangular adosada que forma parte del conjunto, se ha puesto en cuestión a partir de las excavaciones de El Palomar y El Ceremeño, donde Arenas ha identificado unidades domésticas formadas por varios ámbitos constructivos que antes se consideraban casas independientes (Arenas 2007). De tal manera se pone de relieve que la clave para la comprensión del espacio doméstico radica en la identificación de las actividades propias de una unidad doméstica y por tanto, de los espacios donde tendrían lugar en el registro arqueológico.

En este proceso en el que el hábitat se va diversificando y coexisten poblados en llano abiertos con poblados fortificados, con funciones diversas, surgen en las etapas finales de la Edad del Hierro otros asentamientos de grandes dimensiones, los oppida, que han sido identificados como los protagonistas en el desarrollo del fenómeno urbano (Burillo 2007: 260-262, 313-326). Muchos castros se abandonan y se produce una concentración de la población en núcleos cada vez mayores, que se configuran como grandes centros u oppida, como Numancia, Tiermes, Contrebia Leukade, Los Rodiles o Segeda que se convertirán en cabezas jerárquicas de sus ámbitos territoriales (Jimeno 2011: 232; Cerdeño, Chordá y Gamo 2014: 310), y coexisten con pequeños núcleos que perviven como El Castellar de Berrueco 
(Polo y Villagordo 2004) o Herrera de los Navarros (Burillo 1983). La trama interna de los asentamientos de mayores dimensiones amplía el modelo anterior de calle central y se organiza de acuerdo con un urbanismo de tendencia ortogonal con varias calles. "El urbanismo celtibérico en Numancia se muestra como anexión de casas iguales, ordenadas en torno a calles o espacios, como ampliación del esquema inicial de los poblados de calle central" (Jimeno 2011: 252).

Esta nueva forma de hábitat implica una cierta estandarización de la vivienda: "se establece la casa rectangular tripartita como pauta, con el hogar en el centro, el vestíbulo como espacio más público y la despensa en la parte trasera, como espacio más privado, junto con la estancia subterránea para almacenamiento" (Jimeno 2011: 255). Sin embargo, en esta arquitectura doméstica están ausentes los patios centrales o espacios abiertos incluidos dentro de la arquitectura doméstica. El primer ejemplo conocido hasta ahora es el de la denominada Casa del estrígilo de Segeda I.

\section{La Casa del estrígilo de Segeda I}

Las excavaciones y prospecciones arqueológicas llevadas a cabo en el yacimiento de Segeda I (Mara, Zaragoza) (fig. 1) nos ofrecen la imagen de un asentamiento con carácter urbano. Las murallas que lo rodean delimitan un perímetro de cerca de 40 ha., extensión que no llegó a urbanizarse por completo, y que albergaba barrios de arquitectura diversa según muestran las excavaciones realizadas en diferentes partes del conjunto arqueológico (Burillo 2006, 2009). La Casa del estrígilo (Burillo, Cano, López y Saiz 2008; Burillo 2010: 390-392; Fernández, Burillo, Frangani1lo, Gallego, Pérez y Terán e. p. ${ }^{2}$ ), situada a los pies del poyo que constituye el núcleo del asentamiento, representa un cambio notable respecto a los esquemas de las viviendas de las otras zonas, tanto por la planta compartimentada en varias estancias que se organizan en torno a un patio, como por sus dimensiones, $283 \mathrm{~m}^{2}$, que superan ampliamente la superficie de las casas del área 4 , de entre 63 y $76 \mathrm{~m}^{2}$ y las del área 3, de unos

\footnotetext{
2 Fernández García, G., Burillo Mozota, F., Franganillo Rodríguez, D., Gallego Bermúdez, E. Pérez Gutiérrez y M. Terán Manrique, J., e.p.: "La Casa del estrígilo: una mansión de planta helenística en la ciudad celtibérica de Segeda I. Estado actual de la investigación", en: Actas del Congreso Palacios Protohistóricos en el Mediterráneo Occidental (Jaén, 25-28 de noviembre, 2013) Textos CAAI (ed.) Universidad de Jaén.
}

$24 \mathrm{~m}^{2}$. La entrada, localizada en la fachada noroeste, conduce a través de un zaguán al patio central de $35 \mathrm{~m}^{2}$, pavimentado con grandes losas de yeso, que funciona como espacio distribuidor a partir del cual se accede a las once habitaciones que componen la casa. En ellas se han podido reconocer actividades y funciones complementarias que formarían parte del mismo espacio o núcleo doméstico: tres estancias con dos placas de hogar y una tahona para el preparado y el consumo de alimentos, un almacén, una estancia relacionada con la producción metalúrgica y finalmente, tres habitaciones destinadas al reposo (fig. 2c).

En el sistema constructivo se reconocen las técnicas vernáculas que predominan en Segeda y en la arquitectura tradicional de esta región: muros con alzados de adobe y tapial sobre zócalos de piedra, enlucidos de yeso para las paredes, y suelos construidos con morteros de yeso. Estos acabados internos con yeso y cal se emplean en las habitaciones destinadas al reposo, mientras que en el resto, los suelos y paredes están revestidos con arcilla.

El conjunto cerámico hallado en los niveles de abandono y destrucción del asentamiento y de la Casa del estrígilo incluía algunas piezas de importación - fragmentos de ánfora de las últimas producciones grecoitálicas y de Dressel 1A, otra de producción fenicio-púnica denominada "Campamentos Numantinos", así como fragmentos de barniz negro que corresponden con cuencos o copas típicos del círculo de las Campanienses $\mathrm{A}$ - que sitúan cronológicamente el último periodo de vida de Segeda y de ocupación de la Casa del estrígilo durante la segunda mitad del siglo II a. C. (Burillo 2002, 2006; Fernández, Burillo, Franganillo, Gallego, Pérez y Terán e. p.).

En la Casa del estrígilo constatamos la aparición aislada de una casa de patio en el interior peninsular y su desconexión con la arquitectura tradicional protohistórica donde hemos visto una ausencia de precedentes en cuanto a la planta. El elemento de ruptura con la tradición local es el patio como parte orgánica de la casa, pero según hemos referido anteriormente no se desvincula de los sistemas constructivos locales. Los rasgos formales y el periodo de desarrollo de esta vivienda la emparentan con las casas de patio central que durante el periodo helenístico se extienden por el Mediterráneo Occidental, en las cuales contribuyen tanto los aportes de la cultura griega como de la romana, que se mezclan como en el caso de Segeda, con la arquitectura local (Tang 2005; Jolivet 2011: 94). 


\section{Las casas de patio durante la primera romanización}

Las evidencias arqueológicas de la arquitectura doméstica que se desarrolla en el Levante y el Sistema Ibérico durante el inicio del dominio político romano en estos territorios son bastante escasas; sin embargo, los casos conocidos evidencian las consecuencias del nuevo orden político en los espacios domésticos ${ }^{3}$. Las formas de la edilicia doméstica itálica, caracterizadas por su articulación en torno a patios o atrios, comienzan a introducirse y a modificar el hábitat en los asentamientos de origen indígena. En las ciudades de nueva fundación se implantan de forma más generalizada. Como ejemplos del primer grupo señalamos el asentamiento de Numancia, El Cabezo de Alcalá de Azaila, o la ciudad de fundación focea Emporion. Entre las primeras ciudades romanas podemos hacer referencia a las casas de la ciudad romana de Ampurias y a las de La Caridad de Caminreal, que analizamos a continuación.

\section{La casa 2D de El Cabezo de Alcalá de Azaila (Teruel)}

En el Cabezo de Alcalá de Azaila (Teruel) (fig. 1), la arquitectura doméstica documentada a partir del plano de 1929 de las excavaciones de Cabré, incluye varias casas de patio central que abren hacia la calle principal del asentamiento (Beltrán 1991, 2013). La datación de la construcción y uso de estas viviendas resulta difícil por el registro procedente de su excavación realizada a principios de siglo XX y por la ausencia de materiales asociados a las viviendas; lo que también dificulta la interpretación de las funciones de los espacios. Sin embargo, a pesar de la incertidumbre para vincular las pinturas y los pavimentos de opus signinum encontrados en el foso sur del yacimiento con las estructuras arquitectónicas, se señala que "debieron inscribirse en determinadas casas de la acrópolis en el último cuarto del s. II a. C., que se adornaron siguiendo los criterios estéticos y materiales de los esquemas itálicos pertenecientes al Primer Estilo" (Beltrán 2013: 238). Por

\footnotetext{
${ }^{3}$ Para un acercamiento a la edilicia romana tardorrepublicana en Hispania remitimos a las siguientes publicaciones: La casa urbana hispanorromana: ponencias y comunicaciones 1991; Jiménez y Ribera 2002; Uribe Agudo, P. (tesis doctoral inédita) La edilicia doméstica urbana romana en el nordeste de la península ibérica (ss. I a.C. - III d.C.). Departamento de Ciencias de la Antigüedad, Universidad de Zaragoza; Cortés y Guitart 2010; y Cortés 2014a, 2014b.
}

tanto, se asocian a las casas concentradas en la parte central del poblado, en posición privilegiada, articuladas en torno a patios centrales.

Entre ellas, la Casa 2D que ocupa una superficie de $350 \mathrm{~m}^{2}$, es la de mayores dimensiones (fig. 2d). La entrada desde la calle central del asentamiento está precedida por una acera enlosada, al igual que el vestíbulo y el patio rectangular al que nos aboca. A ambos lados del vestíbulo se comunica con las estancias laterales, dos hacia el este y tres hacia el oeste, si bien los accesos están poco claros y bastante alterados por la restauración de 1944. Al fondo del patio hay otras tres estancias, y en el ángulo noreste un recinto dividido en tres partes y que comunica con el exterior (Beltrán 2013: 242-244). La interpretación de las funciones resulta imposible por la ausencia de materiales asociados, como ya hemos señalado, si bien esta lectura se ha realizado en clave a la distribución de una casa itálica, donde el tablinum sería la habitación del fondo, el triclinium ocuparía la habitación de la esquina noroeste, y el resto de las habitaciones se corresponderían con cubicula (Beltrán 1991: 133).

\section{La casa de Likine de La Caridad (Caminreal, Teruel)}

El asentamiento de La Caridad (Caminreal, Teruel) (fig. 1) proporciona una interesante muestra de la arquitectura doméstica de influencia itálica en un núcleo de población que surge durante los primeros años de control romano de este territorio. De todas las estructuras domésticas excavadas, que se enmarcan en una trama urbana ortogonal, la mayor y más suntuosa es la Casa de Likine $\left(915 \mathrm{~m}^{2}\right)$, que se ubica en la ínsula I en el sector noroeste del yacimiento (Vicente, Punter, Escriche y Herce 1991: 81-90) (fig. 2e). El esquema organizativo se desarrolla a partir del amplio patio central porticado de $14,8 \mathrm{~m} \times 15,6 \mathrm{~m}$, que ocupa casi el $25 \%$ de la vivienda, en cuyos cuatro lados se disponen dieciocho estancias. La interpretación de la distribución de los espacios funcionales se ha realizado de acuerdo con la concentración de materiales y del tipo de acabados internos de las habitaciones. De forma general, aquellas donde los suelos aparecen pavimentados con opus signinum o con mortero blanco pintado de rojo sobre un preparado de cantos rodados, se vinculan con espacios de representación. La habitación localizada al fondo del patio, con un rico mosaico con una inscripción interpretada, entre otras lecturas, con el nombre del propietario de la 
casa, Likine $e^{4}$ (Beltrán 2013: 245), ocuparía el espacio del tablinum romano o del oecus helenístico. Las otras dos habitaciones nobles son cubicula situados en los laterales Este y Oeste. En el ángulo suroeste se concentran cuatro estancias dedicadas en principio a actividades artesanales. Mientras que en el ángulo opuesto los materiales asociados a las dos grandes estancias que lo ocupan indican que podrían ser almacenes. En el ángulo noreste, entre otras habitaciones de función indeterminada, se ha detectado un espacio abierto que comunica con el patio y con tres estancias residenciales (Vicente, Punter, Escriche y Herce 1991: 108-112, 121: fig. 62).

La interpretación de este esquema compositivo bien puede seguir la acertada observación de sus excavadores, para los que "la disposición centrípeta se impone a cualquier otra intención de axialidad o simetría y quizás sea el resultado de la unión de dos esquemas compositivos muy difundidos: el propio de la casa de ámbito helénico, con un patio de grandes dimensiones, generalmente con solo tres lados porticados, y el esquema típicamente itálico con la composición clásica de entrada/atrio/tablinum/hortus" (Vicente, Punter, Escriche y Herce 1991: 107).

El corto periodo de ocupación del yacimiento y de la casa se sitúa entre la segunda mitad del siglo II a. C. y la primera del siglo I a. C., a partir, fundamentalmente, de la cronología que ofrecen los materiales cerámicos de importación - Campaniense A y B, ánforas Dressel 1A, 1B, 1C y Brindes, lucernas tipo Broneer I y XI y cerámica de paredes finas tipo Mayet II y III — así como los hallazgos numismáticos (Vicente, Punter, Escriche y Herce 1991: 92-95).

\section{Ampurias, la Casa número 1}

En la arquitectura doméstica de la Neapolis (Emporion) y de la ciudad romana de Ampurias (Emporiae) (fig. 1), dos núcleos urbanos con trayectorias históricas diferentes y la influencia de la edilicia doméstica itálica se funde con otros aportes culturales. Conocemos del panorama urbanístico de Emporion la última fase constructiva, entre el s. II a. C., cuando tienen lugar una reforma urbanística, y el s. I a. C., donde se ha podido

\footnotetext{
${ }^{4}$ La inscripción realizada sobre el pavimento de opus signinum con teselas blancas está redactada en lengua ibérica y habla sobre el propietario de la casa: los estudios epigráficos indican que likinete es un nombre personal, si bien la lectura completa de la frase ha dado lugar a diversas interpretaciones (Beltrán 2010: 247-250). Resulta interesante constatar la pervivencia de la lengua ibérica, probablemente asociada a los habitantes de esta casa con una planta y un estilo decorativo con referentes itálicos.
}

constatar que a pesar de la importancia de las influencias itálicas, perviven elementos griegos, helenísticos, púnicos e iberos. En recientes estudios (Tang 2005: 145-148; Cortés 2014b) sobre las viviendas excavadas en la Neapolis, que toman como partida el análisis de los sistemas y elementos constructivos que forman parte de las casas, se han identificado influencias procedentes de varios ámbitos culturales que forman un paisaje heterogéneo de formas, donde no solo se distinguen ejemplos tributarios de los esquemas itálicos de atrio y peristilo, sino también la presencia de formas helenísticas, púnicas e iberas. La clasificación del panorama urbanístico que propone Cortés está representada por las siguientes líneas constructivas: las casas que pretenden reproducir un esquema itálico de periodo republicano; las casas de concepción griega pero con elementos itálicos, las casas de patio de disposición centrípeta, que representan el porcentaje más alto, y las casas simples multifuncionales (Cortés 2014b: 134). Los restos conservados y estudiados de esta última fase representan los últimos momentos de la misma, es decir, entre el cambio de era y el s. I a. C. Pero entre ellos ha sido posible reconocer la pervivencia de estructuras del periodo republicano que en ocasiones no han sido modificadas y en otras han condicionado las nuevas construcciones. Como vemos, el patio se ha generalizado bajo una forma u otra y de acuerdo con influencias diversas.

Por otro lado, las viviendas de la ciudad de fundación romana son reflejo de "la temprana recepción en la Península de los modelos arquitectónicos característicos de la vivienda urbana itálica" (Santos 1991: 19). La Casa número 1 o Casa Villanueva representa un ejemplo interesante en este punto y para el presente trabajo. La fase inicial de esta vivienda correspondiente al periodo tardorrepublicano, es el núcleo a partir del cual se desarrolla una gran domus de peristilo durante su último momento de uso. En este caso se respeta la estructura más antigua, no como en la vecina domus 2 en la que las sucesivas reformas borraron la disposición inicial. Las dimensiones que alcanza la Casa 1 durante su última fase, $3500 \mathrm{~m}^{2}$, triplican la superficie inicial de la vivien$\mathrm{da}\left(598 \mathrm{~m}^{2}\right)$ y llega a ocupar la totalidad de la ínsula que, al inicio, pudo dar cabida a tres unidades diferentes que acaban siendo asimiladas por esta sola casa (fig. 2f). En la estructura del s. II a. C., sobre la que nos detendremos, la articulación interior está marcada por el eje de simetría tripartito presente en las domus de cavaedium canónicas de la península itálica. En su eje longitudinal, orientado oeste-este, se alinean con la entrada, el pasillo 
o fauces, a cuyos lados se sitúan dos habitaciones en cada lateral, el impluvium del atrio y el tablinum, situado al fondo flanqueado por dos cubicula. Ambos lados del patio, hacia el norte y hacia el sur, están ocupados por tres habitaciones en posición igualmente simétrica. El patio, pavimentado en su primera fase con opus sectile, ocupa un espacio de 143,64 $\mathrm{m}^{2}(13,3 \mathrm{~m} \times 10,8$ m) (Santos 1991: 22-26). La planta de esta vivienda, cuya primera fase se sitúa cronológicamente durante la fundación de la ciudad en torno al año 100 a. C. (Santos 1991: 25), remite por un lado al canon itálico, a pesar de que el espacio de las alae está ocupado por dos habitaciones cerradas, pero también denota influencias helenas (Jolivet 2011: 143).

\section{UN ANÁLISIS SINTÁCTICO DEL ESPACIO DE LAS CASAS DE PATIO DEL NORESTE DE LA PENÍNSULA IBÉRICA ENTRE LOS SIGLOS IV Y II a. C.}

El arco cronológico seleccionado nos permite observar la evolución del elemento arquitectónico del patio en un contexto sujeto a trayectorias y dinámicas regionales e históricas diferentes, pero no desconectadas. En el siglo IV a. C. tan solo algunas viviendas del yacimiento de El Oral presentan este elemento, mientras que durante el siglo III a. C. se hace más frecuente en otros asentamientos ibéricos del litoral mediterráneo. Su aparición en zonas del interior tiene lugar a principios del s. II a. C. de forma aislada, como muestra el caso de Segeda I donde su aparición puede vincularse a la entrada de influencias del Mediterráneo por la intensificación de los contactos con este ámbito. La ocupación romana del noreste, durante el siglo II a. C. impulsará la importación directa de los estilos de viviendas dominantes en el ámbito itálico durante el periodo tardo-republicano que incluyen de forma general el patio, en los que confluyen la influencia itálica y la helenística de patio central.

En el recorrido que hemos realizado por diferentes casas de patio, vemos que los patios se construyen en las casas que manifiestan una voluntad mayor de diferenciación respecto al resto del conjunto de la arquitectura doméstica. En el mundo hispanorromano hay pocas dudas sobre la vinculación de estas casas a las élites de las ciudades. En el ámbito ibérico la asociación de estas viviendas con grupos minoritarios sentido, Álvarez y Asensio (2008: 100) identifican un tipo de grandes residencias, con un posible origen en el siglo IV a. C. con patios abiertos, próximos a murallas, con revestimientos de paredes y pavimentos sofisticados, como el opus signinum y en algunos casos actividades rituales, que consideran "manifestaciones arquitectónicas vinculadas a sectores aristocráticos" (Álvarez y Asensio 2008: 100). Por otro lado, Sala y Abad (2006: 28) consideran importante "enfatizar los aspectos arquitectónicos como elementos de juicio más fiables, es decir, los materiales y técnicas constructivas de un lado y el tamaño de los edificios de otro". En los casos expuestos, el patio se combina con una rica decoración y cuidadosos acabados de muros y pavimentos, grandes dimensiones y materiales de prestigio en sus dependencias. Características que denotan su pertenencia a grupos minoritarios y poderosos que se identifican y representan en la trama urbana mediante una arquitectura diferenciada.

Observamos cómo el patio perdura, bajo formas diferentes, como elemento de distinción y representación de las élites a lo largo de un periodo de tiempo de casi cuatro siglos, durante los cuales se producen cambios en las relaciones políticas y económicas. Por ello, nos proponemos indagar en el conocimiento de los grupos que habitan estas casas a través, precisamente, de su característico espacio doméstico y nos planteamos si acaso se asemejan los comportamientos de los grupos sociales dominantes del periodo prerromano con las élites que se asientan inmediatamente después de la inclusión de estos territorios bajo el control romano.

El análisis sintáctico del espacio construido en Arqueología se propone como una herramienta analítica que permite interpretar los comportamientos de un grupo social a partir de los edificios que éste habita (Bermejo 2014a: 86-87; Grau 2013: 58). Con esta metodología abordamos el análisis de los casos descritos, con el objetivo de conocer el sentido de las casas de patio a lo largo de este periodo de transición. El análisis que sigue se orienta a partir de las siguientes cuestiones clave: en primer lugar, qué características confiere a la vivienda el espacio central abierto del patio que se repite en todos los casos descritos, y en segundo lugar, cuáles son las diferencias en la configuración del espacio interior entre este conjunto de casas de patio. Como habíamos señalado en un trabajo previo en el que analizábamos en solitario la Casa del estrígilo de Segeda I (Fernández e.p.), un estudio comparado de varias plantas de casas de patio a través de la sintaxis espacial podrá ser útil para comprender la complejidad del proceso de transición a partir de los rasgos que perduran y aquellos que mutan y que, de acuerdo con la lógica 
espacial, implican y reflejan cambios en las relaciones del núcleo doméstico y nos acercará a la complejidad de este periodo de transición. Por otra parte, el análisis de las plantas a partir de esta perspectiva permitiría completar un análisis tipológico-descriptivo y proponer una caracterización de este tipo de vivienda, no solo a partir de sus rasgos formales sino también de acuerdo con la lógica social en la que se genera. Según ha planteado Bermejo (2014a: 85-93), los métodos que proporciona la sintaxis espacial complementan un análisis basado en la forma de la planta de las viviendas, con los análisis de los gráficos de accesibilidad (Hillier y Hanson 1984). El estudio de estos gráficos y sus valores numéricos nos permite extraer una serie de características específicas en cuanto a su configuración espacial ${ }^{5}$.

La interpretación de estas características a la luz del contexto histórico servirá para conocer las relaciones sociales que pueden tener lugar dentro de los espacios arquitectónicos y definir patrones espaciales en la arquitectura doméstica y por tanto la lógica de la articulación interior.

\section{Valores descriptivos: superficie, índice de escala e índice de complejidad}

Respecto a la superficie de las casas se pueden diferenciar dos grupos entre los que hay un salto cuantitativo y se triplican las dimensiones: un grupo entre $600 \mathrm{~m}^{2} \mathrm{y}$ $900 \mathrm{~m}^{2}$, que corresponde a etapas más recientes entre la segunda mitad del siglo II a. C. y s. I a. C.; el resto de viviendas, entre 200 y $350 \mathrm{~m}^{2}$, pertenece a contextos previos a la conquista romana, a excepción de la casa de Azaila (fig. 3).

Sin embargo, en los valores del índice de escala, que representa el número de unidades espaciales dentro de una construcción, las diferencias entre un grupo y otro no son tan grandes, sino que reflejan un aumento del número de habitaciones de forma gradual. Igualmente sucede en cuanto a la complejidad, valor que se obtiene mediante la suma del índice de escala y el número de accesos entre ellas. De modo que el aumento de las superficies no se corresponde tan directamente con un aumento de la compartimentación interior y de la complejidad.

En el cálculo de la ratio entre índice de escala y la superficie, que muestra las condiciones de habitabilidad de las viviendas, se afirma la división que marcaba el drástico aumento en las dimensiones de los espacios domésticos. Por lo tanto, en las casas mayores, la complejidad es tan solo ligeramente mayor; en vez de multiplicar el número de estancias, son más amplias y se favorece así las condiciones objetivas de habitabilidad.

\section{La segregación de los espacios: la "Asimetría Relativa"}

Para valorar el grado de segregación o separación entre las habitaciones que generan las compartimentaciones internas de un edificio, la sintaxis espacial utiliza el índice de la "Asimetría Relativa" (fig. 4). Se calcula a partir de la profundidad total y el número de las unidades espaciales del conjunto y se expresa en valores entre 0 y $1^{6}$. De acuerdo con los valores obtenidos podemos diferenciar en primer lugar dos grupos, en función de la diferencia entre los valores mínimos y máximos. Obtenemos un grupo de dos casas, la Casa de Likine de La Caridad y la casa número 1 de Ampurias, con valores más uniformes que los del otro grupo, ligeramente más dispares. De acuerdo con la lectura que plantea Bermejo (2014a: 106-108), refleja un patrón de convivencia

\section{Casa HIV de El Oral}

Casa ํo 2 de El Castellet de Banyoles

Casa del estrígilo de Segeda I

Casa 2D de Azaila

Casa de Likine de La Caridad

Casa núm. 1 de Ampurias

\begin{tabular}{cccc} 
Superficie & Escala & Complejidad & $\begin{array}{c}\text { Ratio área/ } \\
\text { escala }\end{array}$ \\
\hline $209 \mathrm{~m}^{2}$ & 9 & 18 & 23.2 \\
$350 \mathrm{~m}^{2}$ & 10 & 19 & 35 \\
$283 \mathrm{~m}^{2}$ & 13 & 27 & 21.7 \\
$350 \mathrm{~m}^{2}$ & 15 & 31 & 26.92 \\
$915 \mathrm{~m}^{2}$ & 20 & 41 & 47.05 \\
$598 \mathrm{~m}^{2}$ & 17 & 56 & 35.17 \\
\hline
\end{tabular}

Figura 3. Tabla de los valores descriptivos.

\footnotetext{
${ }^{5}$ Para el cálculo del Valor de Control y la Asimetría Absoluta hemos recurrido al software AGRAPH (B. Manum, E. Rusten, P. Benze: AGRAPH, Software for Drawing and Calculating Space Syntax "Node-Graphs" and SpaceSyntax “Axial-Maps". Universidad Noruega de Ciencia). http://www. ntnu.no/ab/spacesyntax/ 12/07/2013.
}

\footnotetext{
${ }^{6}$ La Asimetría Relativa es una manipulación matemática del valor de profundidad de los espacios (TDn) para potenciar sus valores, o resaltar su diferencia. Se calcula a partir de la profundidad total y el número de nodos del conjunto y se expresa en valores entre 0 y 1 .
} 


\begin{tabular}{|c|c|c|c|c|c|c|}
\hline & $\begin{array}{c}\text { Casa HIV de } \\
\text { El Oral }\end{array}$ & $\begin{array}{l}\text { Casa no } 2 \text { de } \\
\text { El Castellet } \\
\text { de Banyoles }\end{array}$ & $\begin{array}{c}\text { Casa del } \\
\text { estrígilo de } \\
\text { Segeda I }\end{array}$ & $\begin{array}{c}\text { Casa 2D de } \\
\text { Azaila }\end{array}$ & $\begin{array}{c}\text { Casa de } \\
\text { Likine de La } \\
\text { Caridad }\end{array}$ & $\begin{array}{l}\text { Casa num. } 1 \\
\text { de Ampurias }\end{array}$ \\
\hline EXTERIOR & 0.3 & 0.32 & 0.34 & 0.63 & 0.22 & 0.19 \\
\hline PATIO & 0.08 & 0.14 & 0.08 & 0.58 & 0.04 & 0.03 \\
\hline 2 & 0.3 & 0.32 & 0.19 & 0.55 & 0.13 & 0.11 \\
\hline 3 & 0.41 & 0.18 & 0.19 & 0.6 & 0.11 & 0.15 \\
\hline 4 & 0.19 & 0.32 & 0.34 & 0.66 & 0.14 & 0.31 \\
\hline 5 & 0.41 & 0.36 & 0.14 & 0.75 & 0.3 & 0.15 \\
\hline 6 & 0.3 & 0.36 & 0.42 & 0.85 & 0.14 & 0.15 \\
\hline 7 & 0.3 & 0.32 & 0.26 & 0.66 & 0.2 & 0.15 \\
\hline 8 & 0.47 & 0.25 & 0.29 & 0.77 & 0.21 & 0.15 \\
\hline 9 & 0.25 & 0.4 & 0.29 & 0.75 & 0.14 & 0.14 \\
\hline 10 & & 0.5 & 0.24 & 2.14 & 0.14 & 0.13 \\
\hline 11 & & 0.58 & 0.24 & 2.14 & 0.22 & 0.14 \\
\hline 12 & & & 0.24 & 2.14 & 0.22 & 0.15 \\
\hline 13 & & & 0.24 & 0.74 & 0.12 & 0.15 \\
\hline 14 & & & & 0.64 & 0.14 & 0.15 \\
\hline 15 & & & & 0.61 & 0.13 & 0.15 \\
\hline 16 & & & & & 0.14 & 0.31 \\
\hline 17 & & & & & 0.13 & 0.15 \\
\hline 18 & & & & & 0.23 & \\
\hline 19 & & & & & 0.14 & \\
\hline 20 & & & & & 0.14 & \\
\hline Mínimo & 0.08 & 0.14 & 0.08 & 0.55 & 0.04 & 0.03 \\
\hline Media & 0.3 & 0.34 & 0.25 & 0.95 & 0.16 & 0.16 \\
\hline Máximo & 0.47 & 0.58 & 0.42 & 2.14 & 0.3 & 0.31 \\
\hline
\end{tabular}

Figura 4. Tabla de los valores de Asimetría Absoluta. En gris claro, los valores más bajos y en gris oscuro, los más altos. estrecho en el que los miembros de la unidad doméstica estarían abocados a compartir espacios. Concretamente lo observamos en las casas de filiación itálica, de donde podemos interpretar que los siervos comparten las habitaciones con los dueños.

Si entramos en un análisis minucioso podemos igualmente observar una serie de comportamientos. En primer lugar, los espacios cuyos valores altos indican mayor segregación, se corresponden con almacenes en el caso de El Oral, de Segeda y de Azaila. Mientras que en las casas del otro grupo, las habitaciones con esta función no están en una posición diferenciada del resto de estancias de la casa, como en la Casa de Likine de La Caridad, donde el almacén se encuentra al lado de la entrada. En segundo lugar, la posición del patio respecto al resto de estancias adquiere los niveles más bajos de Asimetría Absoluta en todos los casos y por tanto es el lugar que mayor integración muestra dentro de la estructura de la vivienda. En Ampurias la habitación al fondo, interpretada como tablinum, y las dos adyacentes comparten con el patio los espacios de menor segregación.

\section{Los patrones de convivencia en los espacios domésticos: la integración}

Como hemos visto, el comportamiento contrario a la segregación, expresado en el valor de Asimetría Relativa, es la integración; se puede calcular para cada una de las unidades espaciales o para el conjunto arquitectónico ${ }^{7}$, opción que nos parece más representativa una vez calculada la segregación de forma individual. El concepto de integración en el análisis espacial se refiere al grado de comunicación de las habitaciones entre sí; es decir, si las interconexiones que pueden existir dentro de un edificio facilitan o dificultan la relación entre los espacios y el movimiento de las personas. Los valores altos indicarán que hay más accesos que habitaciones, y por tanto éstas se mantienen muy comunicadas entre sí. Si hubiera casas con valores inferiores a 1, querría decir que hay

\footnotetext{
7 Según ha sido llevado a la práctica por Bermejo (2009: 55, 2014: 89-90) de acuerdo con la teoría de Blanton (1994), se calcula dividiendo el número de conexiones entre el número de unidades espaciales) y proporciona un valor total para toda la unidad constructiva, al contrario del cálculo que propone Agraph en el que cada unidad adquiere un valor individual.
} 
habitaciones que no están comunicadas. Sin embargo, el valor 1 indica un equilibrio.

En nuestro caso de estudio, los valores que obtenemos se agrupan en torno a 1 o ligeramente lo superan, $\mathrm{y}$ se mantiene la separación que se reflejaba en los cálculos anteriores (fig. 5). En las grandes casas de La Caridad y de Ampurias la arquitectura interna no favorecía la separación o reclusión de personas en ningún ambiente o, según la interpretación de Bermejo (2014a: 105), "vivían bajo patrones de convivencia muy estrechos". En las otras cuatro casas es frecuente la existencia de espacios con menores conexiones y que por lo tanto se sitúan en un plano de profundidad respecto a la entrada o el patio como hemos señalado en el apartado anterior.

\begin{tabular}{lc}
\hline \hline & Integración \\
\cline { 2 - 2 } Casa HIV de El Oral & 1 \\
Casa no 2 de El Callet de Banyoles & 1 \\
Casa del Estrígilo de Segeda I & 1 \\
Casa 2D de Azaila & 0.08 \\
Casa de Likine de La Caridad & 1.05 \\
Casa número 1 de Ampurias & 1.11 \\
\hline
\end{tabular}

Figura 5. Tabla de los valores de Integración.

\section{Valor de control}

Finalmente, las relaciones que posibilita la articulación de los espacios a través de sus accesos, también se puede medir en términos del control; cómo unos espacios son controlados por otros espacios controladores. El Valor de $\mathrm{Control}^{8}$ se calcula asignando a cada unidad espacial un valor de 1 que se reparte equitativamente sobre los espacios con los que conecta, de forma que el valor de control de cada nodo será igual a los valores que recibe de los otros.

En todas las viviendas analizadas el patio siempre tiene los valores más altos; luego es el espacio controlador (fig. 6). Excepto en la vivienda de Azaila, los

\footnotetext{
${ }^{8}$ Para calcular los valores de control (Control Value, CV), no se tiene en cuenta ninguna jerarquía ni dirección y los valores son asignados de forma equitativa a cada espacio. El cálculo es el siguiente: se asigna a cada nodo un valor de 1 que se reparte equitativamente sobre los espacios con los que conecta, de forma que el valor de control de cada nodo será igual a los valores que recibe de los otros. Los valores altos indicarán espacios controladores y los valores bajos espacios controlados.
}

valores distorsionan esta imagen y lo achacamos a la poca fiabilidad que se desprende de la información de que hoy en día disponemos a partir de la reconstitución y restauración de los muros a mediados de siglo XX y que falsean el registro original. En las casas de El Oral, El Castellet de Banyoles y Segeda, los pórticos situados al lado de los patios, así como los receptáculos con hogares y asociados a la cocina, son los espacios de mayor control después del patio. En las casas de La Caridad y de Ampurias, sin embargo, las habitaciones situadas al fondo del patio, interpretadas como el tablinum de la domus, adquieren los valores de control más altos junto con el patio. Nos parece razonable y que concuerda con la función de representación asignada a esta habitación en la cultura itálica. Se evidencia una trasposición de los lugares de importancia desde los espacios de cocina o pórticos hacia los espacios de representación asociados con el dominum de la casa.

Nos preguntamos en consecuencia qué habitaciones se controlan desde estos ámbitos. En primer lugar, el exterior, la calle, aparece con los niveles más bajos de control en los casos de El Oral, El Castellet de Banyoles y Segeda. En El Oral se pueden considerar espacios controlados los tres señalados como habitaciones nobles, mientras que en Segeda sería también el almacén. En las casas de La Caridad y Ampurias casi todas las habitaciones periféricas están igualmente controladas por los espacios señalados.

Podemos extraer la siguiente información a partir del análisis sintáctico comparado de estas seis viviendas de patio (fig. 7). En primer lugar, el aumento de la superficie en las casas de estilo itálico no se corresponde con un aumento de la complejidad interior, sino de una mejora en las condiciones de habitabilidad al disponer de habitaciones más espaciosas. Mientras que en las casas cuya superficie no supera los $350 \mathrm{~m}^{2}$, el aumento del tamaño implica una mayor compartimentación interior que, de acuerdo con la lectura de los ambientes que ha posibilitado el registro arqueológico en algunos casos, se corresponden con espacios de trabajo, cocina o almacenes.

En segundo lugar, si bien en las casas hispanorromanas se ha identificado una convivencia más estrecha, ésta incluye también los espacios de producción, que no están separados del resto de habitaciones de la casa, como en la Casa de Likine, donde las seis estancias dedicadas a almacenaje y a trabajos artesanales están al lado de la entrada y su acceso no presenta ninguna restricción. Por lo tanto, estas actividades relacionadas con el consumo y la producción están controladas dentro de la estructura doméstica. 


\begin{tabular}{|c|c|c|c|c|c|c|}
\hline & $\begin{array}{l}\text { Casa HIV } \\
\text { de El Oral }\end{array}$ & $\begin{array}{l}\text { Casa no } 2 \text { de } \\
\text { El Castellet } \\
\text { de Banyoles }\end{array}$ & $\begin{array}{c}\text { Casa del } \\
\text { estrígilo de } \\
\text { Segeda I }\end{array}$ & $\begin{array}{c}\text { Casa 2D de } \\
\text { Azaila }\end{array}$ & $\begin{array}{l}\text { Casa de } \\
\text { Likine de } \\
\text { La Caridad }\end{array}$ & $\begin{array}{l}\text { Casa num. } 1 \\
\text { de Ampurias }\end{array}$ \\
\hline EXTERIOR & 0.16 & 0.2 & 0.33 & 1.25 & 1 & 2.5 \\
\hline PATIO & 4.83 & 3.75 & 4.91 & 1.08 & 10.16 & 11.83 \\
\hline 2 & 0.16 & 0.2 & 1.47 & 1.83 & 0.57 & 0.4 \\
\hline 3 & 0.33 & 2.7 & 1.47 & 0.75 & 1.57 & 0.07 \\
\hline 4 & 2.16 & 1.25 & 0.33 & 1 & 0.07 & 0.33 \\
\hline 5 & 0.33 & 0.25 & 2.64 & 1.5 & 0.5 & 0.07 \\
\hline 6 & 0.16 & 0.25 & 0.5 & 0.5 & 0.07 & 0.07 \\
\hline 7 & 0.16 & 0.2 & 1.25 & 1.33 & 1.33 & 0.07 \\
\hline 8 & 0.5 & 0.7 & 0.25 & 0.5 & 0.33 & 0.07 \\
\hline 9 & 1.16 & 1.5 & 0.25 & 0.33 & 0.07 & 0.4 \\
\hline 10 & & 0.5 & 0.14 & 0 & 0.07 & 1.07 \\
\hline 11 & & 0.5 & 0.14 & 0 & 0.33 & 0.4 \\
\hline 12 & & & 0.14 & 0 & 0.33 & 0.07 \\
\hline 13 & & & 0.14 & 0.5 & 2.07 & 0.07 \\
\hline 14 & & & & 1.83 & 0.07 & 0.07 \\
\hline 15 & & & & 0.58 & 0.57 & 0.07 \\
\hline 16 & & & & & 0.07 & 0.33 \\
\hline 17 & & & & & 1.07 & 0.07 \\
\hline 18 & & & & & 0.5 & \\
\hline 19 & & & & & 0.07 & \\
\hline Mínimo & 0.16 & 0.2 & 0.14 & 0 & 0.07 & 0.07 \\
\hline Media & 1 & 1 & 1 & 0.81 & 1 & 1 \\
\hline Máximo & 4.83 & 3.75 & 4.91 & 1.83 & 10.16 & 11.83 \\
\hline
\end{tabular}

Figura 6. Tabla con los valores de Control.

\begin{tabular}{|c|c|c|c|c|c|}
\hline $\begin{array}{c}\text { Casa HIV de } \\
\text { El Oral }\end{array}$ & $\begin{array}{c}\text { Casa } 2 \text { de El } \\
\text { Castellet de } \\
\text { Banyoles }\end{array}$ & $\begin{array}{l}\text { Casa del } \\
\text { estrígilo de } \\
\text { Segeda I }\end{array}$ & $\begin{array}{c}\text { Casa 2D de } \\
\text { Azaila }\end{array}$ & $\begin{array}{c}\text { Casa de } \\
\text { Likine de La } \\
\text { Caridad }\end{array}$ & $\begin{array}{l}\text { Casa num. } 1 \\
\text { de Ampurias }\end{array}$ \\
\hline
\end{tabular}

Estilo

formal

Valores

descriptivos

Segregacion
e integración
Casa de patio
Casa de patio con

influencias itálicas
Casa de patio de estilo itálico
Superficies entre 200 y $350 \mathrm{~m} 2$

Progresivo aumento de la complejidad y compartimentación interior

Segregación de almacenes y espacios funcionales
Sup. entre 600 y $900 \mathrm{~m} 2$ No aumenta la complejidad ni la compartimentación interior

Patrón de convivencia estrecho

El patio es el espacio con mayor control sobre el resto

Valor de control
Los pórticos y los ambientes de cocina y trabajo también son controladores
El tablinum tiene altos valores de control junto al patio 
Sin embargo, en las casas prerromanas donde también se incluyen estas funciones, quedan distribuidas en habitaciones con alto grado de segregación y controladas por otras. Los espacios identificados con almacenes en la Casa IVH de El Oral y el almacén de la Casa del estrígilo, demuestran esta idea.

En tercer lugar, el patio, espacio definido en la sintaxis espacial como central y controlador en todos los casos, adopta un carácter diferente al combinarse con las otras habitaciones que también controlan la estructura doméstica. En las casas de estilo itálico los tablina situados al fondo del patio conforman junto al patio un ámbito para la representación y exhibición de los miembros destacados del núcleo doméstico; en este caso, del dominus, cuya habitación por excelencia en la casa era el tablinum. Por otro lado, en el resto de viviendas al lado de los patios, se construyen pórticos y lugares con placas de hogar destinados al preparado de alimentos y a su consumo, y son los lugares preeminentes de la casa. Hay una traslación de los lugares de importancia, desde los destinados la convivencia, hacia los que están relacionados con la representación. Si bien existían espacios más nobles también en las casas de El Oral o Segeda, su localización en la trama interna de la casa les confería un lugar más apartado y con valores de control no muy altos; podemos decir que estaban mejor protegidos. La función que adoptan los patios en las casas de La Caridad y Ampurias recuerda el modelo panóptico de la arquitectura interpretado por Foucault como sistema de control, que Bermejo ha identificado en domus hispanorromanas del periodo tardo republicano e imperial (2014a: 108-110).

\section{CONCLUSIÓN}

La aparente continuidad que se podría desprender del empleo del patio en la arquitectura doméstica de las élites entre el periodo anterior a la conquista romana $\mathrm{e}$ inmediatamente posterior, no encuentra apoyo alguno en el análisis sintáctico realizado. La construcción de casas con patio, si bien crea un espacio central en torno al cual giran las actividades y la vida doméstica, puede dar lugar a viviendas con una sintaxis espacial diferente $\mathrm{y}$, como vemos, no siempre determina modelos panópticos, asociados a las formas de vida de las élites romanas. De modo que a pesar de que nuestra selección de casos comparta este espacio central, encontramos una ruptura entre las casas del primer grupo -El Oral,
Banyoles, Segeda, Azaila - y las del segundo — La Caridad y Ampurias - . La distribución de funciones en la organización interna, muestra viviendas cuyos núcleos domésticos son reflejo de estructuras sociales diferentes. De acuerdo con la lógica del análisis sintáctico derivaríamos de los datos extraídos, la interpretación de las relaciones sociales de los habitantes de las viviendas que necesariamente ha de insertarse en el contexto político, económico y social estudiado.

Las casas ibéricas de El Oral y de El Castellet de Banyoles reflejan un cambio notable, respecto a la tónica general del urbanismo ibérico, que radica en un aumento de la complejidad y del tamaño, para cuya organización se deja un espacio interior abierto. La ampliación del espacio doméstico en este contexto histórico se ha explicado de diversas maneras, bien con la presencia y consolidación de grupos dominantes basados en familias extensas o bien con la inclusión de trabajo dentro de la vivienda y la consiguiente generación y acumulación de más excedente. Esto se hace patente en algunas casas con la integración de ciertas actividades productivas y medios de producción dentro del ámbito doméstico (Grau 2013: 65). En El Castellet de Banyoles, la formación de la aristocracia local se explica a partir de fundamentos económicos como la producción metalúrgica o el control de la producción de cereal (Álvarez, Asensio, Jornet, Miró y Sanmartí 2008: 100).

Sin embargo, la acumulación de funciones como base para la riqueza, no es óbice para descartar un aumento del núcleo doméstico, ya que ambos factores bien pueden estar relacionados. Belarte acude a los ejemplos etnográficos donde las élites poseen grupos extensos porque controlan más recursos y aseguran un mayor número de funciones que a su vez podrían implicar un mayor número de habitantes en la vivienda (Belarte 2013: 89). La relación entre estos numerosos componentes del núcleo doméstico estaría regida, de acuerdo con Grau (2013: 66), por los lazos de parentesco que caracterizan las relaciones sociales en el mundo ibérico. La interesante aportación de Gorgues (2008) propone identificar a las grandes familias del noreste peninsular que habitaban en las casas complejas como familias extensas cuya base económica eran precisamente la producción doméstica. Para Gorgues el estudio del espacio doméstico entre los íberos es un lugar privilegiado para entender las actividades de producción. En las casas se han encontrado utensilios para el desarrollo de trabajos de distinto tipo, desde la forja hasta el hilado, el tejido, la molienda y la preparación culinaria; también es el 
lugar donde se guardan los aperos de labranza, el grano y otros alimentos y los objetos procedentes del comercio a larga distancia y del intercambio (Gorgues 2008: 174-175). En ciertas estructuras domésticas de notable tamaño y complejidad, se han encontrado evidencias de producción especializada, como el tejido o la forja, que revelaría cómo estas familias extensas podían asumir una mayor carga de trabajo al emplear a todos los miembros del núcleo doméstico, incluidas las mujeres que tendrían un papel esencial en las producciones domésticas. El control de esta producción especializada asegura la influencia de estas grandes familias sobre los otros grupos domésticos menores, de tipo nuclear, con producciones orientadas al autoconsumo (Gorgues 2008). En las casas analizadas en el presente trabajo cuyo registro arqueológico ha permitido la interpretación de la funcionalidad de los espacios, se observa siempre la presencia de habitaciones dedicadas al almacenaje y a actividades artesanales. En la Casa IVH de El Oral del conjunto de nueve habitaciones que forman la casa, dos son almacenes; en la Casa del estrígilo, tan solo se ha podido determinar uno; y en la casa hispanorromana de Likine de las diecinueve habitaciones, seis están dedicadas a almacenes y talleres artesanales. Por lo tanto, en el aumento del espacio doméstico implica la asunción de más trabajo doméstico.

La Casa del estrígilo de Segeda en términos formales refleja la introducción de unos rasgos de influencia mediterránea, pero cuya sintaxis espacial recuerda las casas complejas ibéricas. Muestra un momento de transición en el que los núcleos domésticos de las élites introducen elementos culturales del ámbito cultural del Mediterráneo, perolas relaciones sociales no habían llegado a cambiar. Por lo tanto, el paralelismo formal que se podría establecer entre la Casa del Estrígilo y la Casa del Likine, a nivel sintáctico resulta muy débil.

Durante el siglo III a. C. se ha constatado la influencia helenística en diversos ámbitos de la península ibérica, tanto en el Levante, en el nordeste, como en otras zonas del interior, por la aparición de elementos o rasgos del amplio repertorio helenístico, griego, fenicio o púnico, formando parte de la cultura indígena. Una de las expresiones arquitectónicas que se hacen eco de estas influencias son las fortificaciones, murallas y torres de este periodo. El análisis de estas influencias de Moret (2006) a través de una serie de ejemplos del nordeste y del sur peninsular, revela un origen púnico en cuanto a los elementos arquitectónicos empleados y lo que es de más interés para el presente trabajo, que dichas innovaciones no responden a mejoras técnicas solamente, sino a la búsqueda de elementos de diferenciación, marcas de prestigio y ruptura con la arquitectura local y se inscriben en una corriente de monumentalización de los lugares de poder (Moret 2006: 209-214). En esta línea podría interpretarse la adopción de casas con patio, como la adaptación o reinvención local de una forma importada, que no supone una ruptura formal con los esquemas sociales tradicionales, que perduran detrás de diferentes fachadas.

La ruptura con el sistema social tradicional o prerromano se produce más tarde y lentamente, cuando el poder romano empieza a consolidarse en el territorio. La casa 2D de Azaila, a pesar de la escasa fiabilidad que comporta su registro arqueológico, reflejaría en principio la lenta adaptación al nuevo orden social y económico, donde la estructura interna se mantiene apegada a la tradición y mutan tan solo algunos elementos formales. Sin embargo, en ciudades de nueva planta como La Caridad y Ampurias, las élites utilizan el espacio doméstico, no solo como lugar donde concentrar espacios para la producción, sino también para la auto-representación y exhibición, como ya hemos señalado, del señor de la casa con el tablinum. Las grandes domus se configuran de acuerdo con criterios de comodidad y amplitud y no tanto de complejidad. Incluso podríamos afirmar de acuerdo con la expresión arquitectónica de las élites hispano-romanas, que su posición en la sociedad está mucho más asentada y es más estable que en la estructura social anterior. Esta idea se desprende de la diferente posición en la casa de los espacios más nobles y de los almacenes: en las casas prerromanas ni se exhiben ni ocupan espacios de fácil acceso, como sí sucede con los espacios de representación bien visibles y accesibles de las casas hispano-romanas. Sin embargo, las inscripciones que hemos referido de la Casa número 1 de Ampurias o la Casa de Likine, serían un indicio de la identidad cultural de las élites hispanoromanas, vinculada con el sustrato cultural prerromano, celtíbero en un caso, griego en otro.

En estos dos modelos de unidades domésticas y por tanto de relaciones sociales, vemos la traslación de la importancia del grupo o conjunto de todos los habitantes de la casa del dominus con su propio espacio de representación. El grupo doméstico que encabeza, dado que las relaciones sociales que se producen dentro del núcleo doméstico dependen de las relaciones sociales dominantes en el sistema económico en el que se encuentren, incluirá no solo miembros consanguíneos, sino también siervos y esclavos por relaciones de dependencia. 
Como apuntábamos al inicio el ritmo del cambio social se produce de forma muy gradual. Las élites que podemos reconocer en las casas complejas y con patio del siglo III a. C. manifiestan un comportamiento diferente al de las élites que se instalan tras la dominación romana. La adaptación de esta clase social al nuevo orden tiene lugar de forma paulatina; a pesar de la introducción de ciertos rasgos formales de origen externo en momentos previos a la conquista romana, como el patio en las casas del interior peninsular, no se produce una importación e instalación de una lógica social nueva y foránea, sino que hay una recepción y adaptación de estos elementos por la sociedad receptora, que como agentes activos dentro del proceso de intercambio cultural, también transforman e integran estos elementos dentro sus propias relaciones sociales.

\section{AGRADECIMIENTOS}

Este trabajo se desarrolla dentro del proyecto $\mathrm{I}+\mathrm{D}$ : HAR2012-36549 "Segeda y la Serranía Celtibérica: de la Investigación Interdisciplinar al Desarrollo de un Territorio", financiado por el Ministerio de Economía y Competitividad y los fondos FEDER.

\section{BIBLIOGRAFÍA}

Adánez Pavón, J. 2003: "Una conceptuación de la organización espacial doméstica: morfología y dinámica” Revista Española de Antropología Americana extraordinario 35 pp. 35- 53.

Álvarez, R., Asensio, D., Jornet, R., Miró, M. T. y Sanmartí, J. 2008: "Residències aristocràtiques al mon ibèric septentrional. El cás del Castellet de Banyoles (Tivissa, Ribera d'Ebre, Tarragona)”, en J. Blánquez, S. González y L. Roldán (eds.) La Cámara de Toya y la arquitectura monumental ibérica Serie Varia 7 pp. 87-102. Universidad Autónoma de Madrid.

Asensio, D., Sanmartí, J., Jornet, R., Miró, M. 2010: "L’urbanisme i l'arquitectura domèstica de la ciutat ibérica del Castellet de Banyoles (Tivissa, Ribera d'Ebre)", en M. C. Belarte, J. A. Benavente, L. Fatás, D. Jordi, P. Moret y J. Noguera (eds.) Iberos del Ebro. Actas del II Congreso Internacional (Alcañiz-Tivissa, 16-19 de noviembre de 2011) pp. 173-193. Institut Català d'Arqueologia Clàssica. Tarragona.

Arenas Esteban, J. A. 1999: La Edad del Hierro en el Sistema Ibérico Central, España, B.A.R., International Series S780, Oxford.

Arenas Esteban, J. A. 2007: "Sociedad, ideología y entornos construidos durante la protohistoria del oriente meseteño: el caso de El Ceremeño de Herrería", Trabajos de Prehistoria 64, 1, enero-junio 2007, pp. 121 136.

Arenas Esteban, J.A. 2010: “Arquitectura doméstica prerromana del oriente meseteño: análisis funcional y estimaciones demográficas", en F. Burillo Mozota (ed.) Arqueología de la Población. Arqueología Espacial 28, pp. 335-350. Seminario de Arqueología y Etnología Turolense. Teruel.

Arenas Esteban, J.A. 2011: "El poblamiento prerromano en el área del Alto Tajo-Alto Jalón” Complutum 2011, 22 (2) pp. 129-146.
Arlegui, M. 1992: "El yacimiento celtíbero de Castilmontán, Somaén (Soria): El sistema defensivo" II Symposium de Arqueología Soriana. Homenaje a Teógenes Ortego y Frías (19-21 de octubre de 1989), vol. I pp. 495-513. Diputación provincial de Soria.

Azcárate Garay-Olaun, A. 2008: "La arqueología de la arquitectura en el siglo XXI" Arqueología de la Arquitectura, 5, pp. 11-13.

Manum, B., Rusten, E., Benze, P.: AGRAPH, Software for Drawing and Calculation Space Syntax "Node-Graphs" and Space Syntax "AxialMaps”, (http://www.ntnu.no/ab/spacesyntax/, consultado el: 12/07/2013) Universidad de Noruega.

Belarte, M. C. 1997: Arquitectura domèstica i estructura social a la Catalunya protohistórica. Arqueo Mediterrània, 1, Barcelona.

Belarte, M. C. 2008: "Domestic architecture and social differences in NorthEastern Iberia during the Iron Age (c.525-200 BC)", Oxford Journal of Archaeology 27 (2), 175-199.

Belarte, M. C. 2013: "El espacio doméstico y su lectura social en la protohistoria de Cataluña (s. VII- II/I a.C.)", en S. Gutiérrez e I. Grau (eds.) De la estructura doméstica al espacio social. Lecturas arqueológicas del uso social del espacio, pp. 77-94. Alicante.

Belarte, M. C., Bonet, H. y Sala, F. 2009: “L'espai domèstic i l'organització de la societat ibérica: elsterritoris de la franja mediterrània”, en M. C. Belarte (ed.) L'espaidomèstic i l'organització de la societat a la protohistòria de la Mediterrània occidental (1er millenni aC) Actes de la IV Reunió internacional d'Arqueologia de Calafell. Arqueo Mediterrània, 11, 93-123, Barcelona.

Beltán Lloris, M. 1976: Arqueología e historia de las ciudades antiguas del Cabezo de Alcalá de Azaila (Teruel). Zaragoza.

Beltrán Lloris, M. 1991: "La colonia Celsa", en La casa urbana hispanorromana: ponencias y comunicaciones. Institución Fernando el Católico (eds.), pp. 131-164, Zaragoza.

Beltrán Lloris, M. 2013: “Azaila. Estado de la cuestión en el año 2013", Caesaraugusta, 83.

Bermejo Tirado, J. 2009: "Leyendo los espacios: una aproximación crítica a la sintaxis espacial como herramienta de análisis arqueológico", Arqueología de la Arquitectura, 6, pp. 47-62.

Bermejo Tirado, J. 2014a: Arqueología biopolítica. La sintaxis espacial de la Arquitectura doméstica romana en la Meseta Oriental. Ed. La Ergástula, Madrid.

Bermejo Tirado, J. 2014b: "Household Archaeology y el análisis de las sociedades antiguas en la península Ibérica: definiciones, aplicaciones y posibilidades", Materialidades. Perspectivas en cultura material. Institut d'estudis baleàrics, Universitat de les IllesBalears, 2, pp. 47-92.

Blanton, R. E. 1994: Houses and households: A Comparative Study (Interdisciplinary Contribution to Archaeology). London \& New York. PlenumPress.

Burillo Mozota, F. 1983: El poblado de época ibérica y yacimiento medieval: Los Castellares (Herrera de los Navarros, Zaragoza) Institución Fernando el Católico. Zaragoza.

Burillo Mozota, F. 2002: "Indicadores cronológicos para la datación de los niveles de destrucción de Segeda I" Kalathos 20-21, Revista del Seminario de Arqueología y Etnología Turolense. pp. 215-238.

Burillo Mozota, F. 2006: "La ciudad-estado de Segeda I" en F. Burillo Mozota (ed.) Segeda y su contexto histórico. Entre Catón y Nobilior (195 al 153 a.C.). Homenaje a Antonio Beltrán Martínez, pp. 203-240. Centro de Estudios Celtibéricos de Segeda, Zaragoza.

Burillo Mozota, F. 2007: Los celtíberos. Etnias y estados. (Segunda edición actualizada). Ed. Crítica. Barcelona.

Burillo Mozota, F. 2009: "Espacio doméstico en la Celtiberia de los belos", en C. Belarte (ed.) L'espai domèstic i l'organització de la societat a la protohistòria de la Mediterrània occidental (Ier mil.lenni $a C$ ), Actes de la IV Reunió Internacional d'Arqueologia de Calafell, Arqueomediterrània 11, 2009, Treballs de l'àrea d'arqueologia de la Universitat de Barcelona, pp. 165-188.

Burillo Mozota, F. 2010. "Influjos helenísticos en la ciudad celtibérica de Segeda I", Palaeohispanica 10, Serta Palaeohispanica. Homenaje a J. de Hoz pp. 381-404. 
Burillo Mozota, F., Cano Díaz, M. A., López Romero, R. y Saiz Carrasco, M. E. 2008. La casa del estrígilo de Segeda I. Fundación Segeda- Centro Celtibérico.

Cerdeño, M. L., Chordá, M. y Gamo, E. 2014: "Huellas arqueológicas de la conquista romana en Celtiberia: el oppidum de "Los Rodiles" (Guadalajara, España)", en François Cadiou y Milagros Navarro Caballero (eds.) La guerre et ses traces. Conflits et sociétés en Hispanie à l'époque de la conquête romaine (III ${ }^{e}-I^{e r}$ s. a.C.) Ausonius Mémoires 37, pp. 297-317. Bordeaux.

Clarke, D. 1977: "Spatial analysis in archeology", en Clarke, (ed.) Spatial archaeology, pp. 1-32. Academic Press. Londres.

Cortés Vicente, A. 2014a: "Clasificación tipológica de la arquitectura doméstica romana. Reflexiones a partir de las ciudades del NE peninsular", Pyrenae, 45, 2 pp. 59-93.

Cortés Vicente, A. 2014b: "La vivienda de Emporion: un ejemplo de una sociedad ecléctica en el Mediterráneo occidental en época clásica” Lucentum XXXIII pp. 123-136.

Cortés i Vicente, A. y Guitart i Duran, J. 2010: "La Arqueologia de la casa romana en Cataluña", Bolettino di Archeologia on line. Volume Speciale. Roma 2008. International Congress of Classical Archaeology Meetings between Cultures in the Ancient Mediterranean.

Fernández García, G. 2015: "La percepción del espacio interior en la Casa del Estrígilo de Segeda I (Mara, Zaragoza)", en A. Maximiliano y E. Cerrillo-Cuenca (eds.) Arqueología y tecnología de información espacial: una perspectiva ibero-americana. Actas del I Simposio Internacional de Análisis Espacial en Arqueología. Pp. 151-167. Archaeopress Publishing Ltd. Oxford.

Gorgues, A. 2008: "Structure domestique, structure de la production: le travail des femmes dans le nord-est du domaine ibérique (III ${ }^{\mathrm{e}} \mathrm{I}^{\mathrm{er}} \mathrm{S}$. av.J.-C.)" Pallas, 76, 2008, pp. 173-201.

Grau, I. 2013: "Unidad doméstica, linaje y comunidad: estructura social y su espacio en el mundo ibérico (ss. VI-I a.C.)”, en: Gutiérrez y Grau (eds.) De la estructura doméstica al espacio social. Lecturas arqueológicas del uso social del espacio, pp.57-76. Alicante.

Hillier, B. y Hanson, J. 1984: The social logic of space. C.U.P Cambridge.

Jiménez Salvador, J. L. y Ribera i Lacomba, A. 2002: Valencia y las primeras ciudades romanas de Hispania. Valencia, 2002.

Jimeno Martínez, A. 2011: "Espacio doméstico y sociedad en la Celtiberia ulterior", en: M.C. Belarte (ed.) L'espai domèstic i l'organització de la societat a la protohistòria de la Mediterrània occidental (1er millenni aC) Actes de la IV Reunió internacional d'Arqueologia de Calafell. ArqueoMediterrània, 11, Barcelona, pp. 189-212.

Jolivet, V. 2011: Tristes portiques: sur le plan canonique de la maison étrusque et romaine des origines au principat d'Auguste (VIe-Ier siècles av. J.-C.), École française de Rome.

Mañana Borrazás, P., Blanco Rotea, R. y Ayán Vila, X. M. 2002: Arqueotectura 1: Bases teórico-metodológicas para una Arqueología de la Arquitectura. TAPA 25, Trabalhos de Arqueoloxia e Patrimonio. Santiago de Compostela, 2002.

Moret, P. 2006: "Architecture indigène et modèles hellénistiques : les amgiuïtés du cas ibérique", Pallas, 70, 2006, pp. 207-227.

Ortega Ortega, J. M. 1999: “Al margen de la «identidad cultural»: historia social y economía de las comunidades campesinas celtíberas", en Burillo Mozota, F. (coord.) Economía. IV Simposio sobre Celtiberos, pp. 417-445. Institución "Fernando el Católico", Zaragoza.

Polo Cutando, C. y Villargordo Ros, C. 2004: "Del poblado fortificado al asentamiento en llano: la evolución de los asentamientos rurales en el Sistema Ibérico Central (s. III a. C. - I d. C.)”, P. Moret y T. Chapa Brunet (eds.) Torres, atalayas y casas fortificadas: explotación y control del territorio en Hispania (s. III a. de C.- s. I d. de C.), pp. 157-174.

Sala Sellés, F. y Abad Casal, L. 2006: “Arquitectura monumental y arquitectura doméstica en la Contestania" Lucentum 25, pp. 23-46.

Sanmartí, J., Asensio, D., Miró, M. T. y Jornet, R. 2012: “El Castellet de Banyoles (Tivissa): Una ciudad ibérica en el curso inferior del río Ebro" Archivo Español de Arqueología 85, pp. 43-63.

Santos Retolaza, M. 1991: "Distribución y evolución de la vivienda urbana tardorrepublicana y altoimperial en Ampurias", en La casa urbana hispanorromana: ponencias y comunicaciones (Congreso celebrado en Zaragoza del 16 al 18 de noviembre de 1988), Institución Fernando el Católico (eds.), pp. 19-34. Zaragoza.

Tang, B. 2005: Delos, Cathage, Ampurias: TheHousing of ThreeMediterranean Trading Centres, L'Erma di Bretschneider.

Vicente Redón, J. D., Punter Gómez, M. P., Escriche Jaime C. y Herce San Miguel, A. I. 1991: "La Caridad (Caminreal, Teruel)", en La casa urbana hispanorromana: ponencias y comunicaciones (Congreso celebrado en Zaragoza del 16 al 18 de noviembre de 1988), Institución Fernando el Católico (eds.), pp. 81-164. 